\title{
Voltage Profile Analysis during Fault with STATCOM
}

\author{
Amit Debnath \\ Deptt. Of Electrical Engineering \\ Tripura University (A Central University) \\ India
}

\author{
Champa Nandi \\ Assistant Professor \\ Deptt. Of Electrical Engineering \\ Tripura University, India
}

\begin{abstract}
This paper deals with comparative study of voltage and angle stability analysis with and without STATCOM. This paper makes the assumption that under voltage is caused by a Single phase to ground fault. Single phase to ground fault is applied in IEEE 57 bus system for analysis the effected voltage dip area in IEEE 57 bus system. The effect of fault on voltage profile and angle of IEEE 57 bus system has been analyzed with and without STATCOM. The studies are performed based on MATLAB software package tool box.
\end{abstract}

\section{General Terms}

STATCOM FACTS Controller Algorithm, Fault Algorithm, FACTS, MATLAB software package tool box.

\section{Keywords}

Power flow, STATCOM, FACTS Controller, Single line to ground fault, under voltage

\section{INTRODUCTION}

Power flow is very important tool for the analysis power systems and it is used in operational and planning [2]. They are necessary for economic scheduling and exchange of power between utilities. In this analysis, iterative techniques are used due to there no known analytical method to solve the problem. This resulted nonlinear set of equations or called power flow equations are generated. The principal information of power flow analysis is to find the unspecified bus voltage angles and magnitudes, active and reactive powers, [6] as well as line loadings and their associated real and reactive losses for certain generation and load conditions. Recent attention on the providing \& demanding of power to the entire load while maintaining the voltage magnitude at an acceptable range is one of the major system constraints in transmission and distribution of power system. Power Generation and Transmission is a complex process, requiring the working of many components of the power system in tandem to maximize the output. One of the main components to form a major part is the reactive power in the system. It is required to maintain the voltage to deliver the active power through the lines. Loads like motor loads and other loads require reactive power for their operation. To improve the performance of ac power systems, we need to manage this reactive power in an efficient way and this is known as reactive power compensation. There are two aspects to the problem of reactive power compensation: load compensation and voltage support. Load compensation consists of improvement in power factor, balancing of real power drawn from the supply, better voltage regulation, etc. of large fluctuating loads.
Voltage support consists of reduction of voltage fluctuation at a given terminal of the transmission line. Two types of compensation can be used series and shunt compensation. These modify parameters of the system to give enhanced VAR compensation. The VAR compensators like the STATCOM have been developed. The development and use of STATCOM FACTS controllers for power transmission systems has led to the application of these controllers to improve the stability of power networks [3] [4]. Many studies have been carried out and reported in the literature on the use of these controllers in a variety of voltage stability applications, proposing diverse control schemes and location techniques for enhancing voltage oscillation control [5].These quite satisfactorily do the job of absorbing or generating reactive power with a faster time response and come under Flexible AC Transmission Systems (FACTS). This allows an increase in transfer of apparent power through a transmission line, and much better stability by the adjustment of parameters that govern the power system i.e. current, voltage, phase angle, frequency and impedance. In a transmission line three phase fault occur in order of frequency of occurrence. The path of fault current may have either zero impedance, which is called a bolted short circuit, or nonzero impedance. When this types of three phase faults occurs the magnitude of bus voltage cannot exist the suitable range, either voltage drops or high. To prevent this effect, STATCOM FACTS controller is the best solution for maintain bus voltage magnitude in a suitable range [9].

\section{STATCOM OVERVIEW}

A static synchronous compensator (STATCOM), also known as a "static synchronous condenser" ("STATCON"), is a regulating device used on alternating current electricity transmission networks [7]. STATCOM is a self commutated switching power converter supplied from an appropriate electric energy source and operated to produce a set of adjustable multiphase voltage, which may be coupled to an AC power system for the purpose of exchanging independently controllable real and reactive power. The controlled reactive compensation in electric power system is usually achieved with the variant STATCOM configurations. The STATCOM has been defined with following three operating structural components. First component is Static: based on solid state switching devices with no rotating components; second component is Synchronous: analogous 


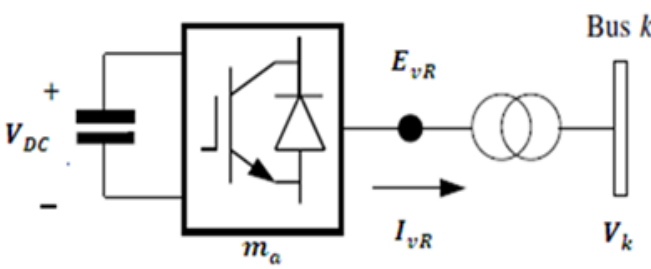

Fig 1: Static compensator (STATCOM) system: voltage source converter (VSC) connected to the AC network via a shunt-connected transformer.

to an ideal synchronous machine with three sinusoidal phase voltages at fundamental frequency and the third component is Compensator: provided with reactive compensation. It is based on a power electronics voltage-source converter and can act as either a source or sink of reactive ac power to an electricity network. If connected to a source of power it can also provide active ac power. It is a member of the FACTS family of devices. Usefully a STATCOM is installed to support electricity networks that have a poor power factor and often poor voltage regulation and the most common use is for voltage stability. A Static synchronous compensator is a voltage source converter based device, with the voltage source behind a reactor. The voltage source is created from a DC capacitor and therefore a Static synchronous compensator has very little active power capability. However, STATCOM active power capability can be increased if a suitable energy storage device is connected across the dc capacitor. The reactive power at the terminals of the Static synchronous compensator depends on the amplitude of the voltage source. For example, if the terminal voltage of the voltage source converter (VSC) is higher than the ac voltage at the point of connection, the STATCOM generates reactive current and when the amplitude of the voltage source is lower than the ac voltage, it absorbs reactive power. The response time of a STATCOM is shorter than that of a static Var compensator (SVC), mainly due to the fast switching times provided by the IGBTs of the voltage source converter. The STATCOM also provides better reactive power support at low ac voltages than an SVC, since the reactive power from a STATCOM decreases linearly with the ac voltage (as the current can be maintained at the rated value even down to low ac voltage).

\subsection{STATCOM Operating Principle}

A STATCOM consists of a coupling transformer, an inverter and a DC capacitor as shown in Figure 2.

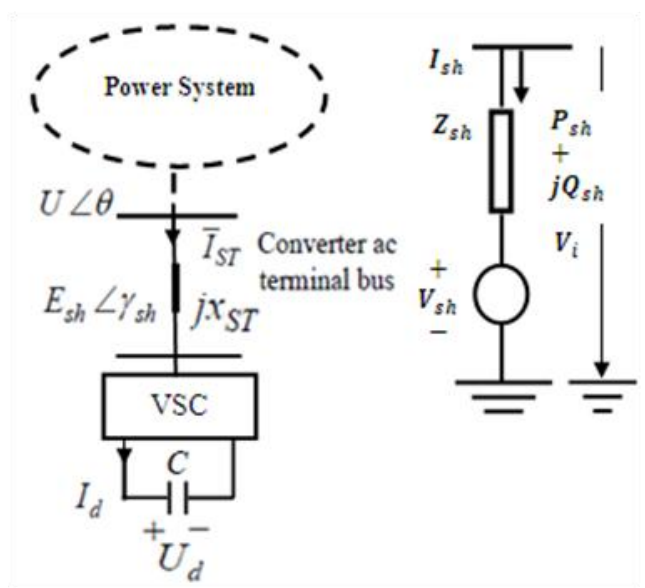

Fig 2: Structure and equivalent circuit of STATCOM
In the ideal steady state analysis, it has been assumed that the active power exchange between the $\mathrm{AC}$ system and the STATCOM has been neglected and only the reactive power has been exchanged between them. STATCOM is usually used to control transmission voltage by reactive power shunt compensation. Based on the operating principle of the STATCOM [8] the equivalent circuit has been derived, which is evident in Figure 2. In the derivation, it is assumed that the harmonics generated by the STATCOM as neglected and the system as well as the STATCOM as three phases balanced. The STATCOM has been equivalently represented by a controllable fundamental frequency positive sequence voltage source $\mathrm{V}_{\mathrm{Sh}}$. In principle of the STATCOM output voltage can be regulated in such a way that the reactive power of the STATCOM can be changed.

\subsection{Modeling of STATCOM}

From the equivalent circuit of the STATCOM shown in figure 2 [7] $\mathrm{V}_{\mathrm{sh}}=\mathrm{V}_{\mathrm{sh}}<\theta_{\mathrm{sh}}, \mathrm{V}_{\mathrm{i}}=\mathrm{V}_{\mathrm{i}}<\theta_{\mathrm{i}}$. Let then the power flow constraints of the STATCOM are:

$$
\begin{aligned}
& P_{s h}=V_{i}^{2} g_{s h}-V_{i} V_{s h} g_{s h} \cos \left(\theta_{i}-\theta_{s h}\right)-V_{i} V_{s h} b_{s h} \\
& \sin \left(\theta_{i}-\theta_{s h}\right) \\
& Q_{s h}=-V_{i}^{2} b_{s h}-V_{i} V_{s h} g_{s h} \sin \left(\theta_{i}-\theta_{s h}\right)+V_{i} V_{s h} b_{s h} \\
& \cos \left(\theta_{i}-\theta_{s h}\right)
\end{aligned}
$$

Where,

$\mathrm{g}_{\mathrm{sh}}+\mathrm{j} \mathrm{b}_{\mathrm{sh}}=\frac{1}{\mathrm{Z}_{\mathrm{sh}}}$

The operating constraint of the STATCOM is the active power exchange via the DC link. i.e. Analysis and Comparison of power flow control and power transfer capability in a Long Transmission Line using Shunt FACTS devices.

$$
\mathrm{PE}=\operatorname{Re}\left(\mathrm{V}_{\text {Sh }} \mathrm{I}_{\text {Sh }}^{*}\right)=0
$$

Where,

$$
\begin{aligned}
& \operatorname{Re}\left(V_{s h} I_{s h}^{*}\right)=V_{s h}^{2} g_{s h}-V_{i} V_{s h} g_{s h} \cos \left(\theta_{i}-\theta_{s h}\right)- \\
& V_{i} V_{s h} b_{s h} \sin \left(\theta_{i}-\theta_{s h}\right)
\end{aligned}
$$

\subsection{STATCOM Control Strategy}

STATCOM was used for controlling the bus voltage, reactive power injection, impedance and current magnitude. Among these control options control of bus voltage of the local, which the STATCOM are connected to, is the most recognized control function. The mathematical descriptions of the control functions are [6]

\subsection{Bus Voltage Control}

The bus control constraint is

$\mathrm{V}_{\mathrm{i}}-\mathrm{V}_{\mathrm{i}}^{\text {spec }}=0$

Where $\mathrm{V}_{\mathrm{i}}^{\text {spec }}$ is the bus voltage control reference

\subsubsection{Reactive Power Control}

In this control mode, reactive power generated by the STATCOM is controlled to a reactive power injection reference. The control constraint is

$$
\mathrm{Q}_{\mathrm{sh}}-\mathrm{Q}_{\mathrm{sh}}^{\mathrm{spec}}=0
$$




\subsubsection{Impedance Control}

STATCOM compensation can be equivalently represented by an imaginary impedance or reactance. In this control mode $\mathrm{V}_{\text {sh }}$ is regulated to control the equivalent reactance of the STATCOM to a specified reactance reference

$\mathrm{X}_{\text {shunt }}-\mathrm{X}_{\text {shunt }}^{\text {spec }}=0$

Where, $\mathrm{X}_{\text {shunt }}^{\mathrm{spec}}$ is the specified reactance control reference of the STATCOM and $\mathrm{X}_{\text {shunt }}$ is the equivalent reactance of the STATCOM

\section{STATCOM POWER FLOW MODEL}

Supposing that the voltage across the STATCOM is $\mathrm{V}_{\mathrm{st}}<\delta_{\mathrm{st}}$ and the voltage of the bus is $\mathrm{V}_{\mathrm{p}}<\delta_{\mathrm{p}}$ then we have,

$$
\mathrm{Y}_{\mathrm{st}}=\frac{1}{\mathrm{Z}_{\mathrm{st}}}=\mathrm{g}_{\mathrm{st}}+\mathrm{j} \mathrm{b}_{\mathrm{st}}
$$

Then the power flow constraints of the STATCOM are given by [1]:

$$
P_{S t}=V_{P}^{2} g_{S t}-V_{P} V_{s t}\left(g_{s t} \cos \left(\theta p-\theta_{s t}\right)+b_{s t} \sin \left(\theta p-\theta_{s t}\right)\right)
$$

$\mathrm{Q}_{\mathrm{st}}=-\mathrm{V}_{\mathrm{P}}^{2} \mathrm{~g}_{\mathrm{st}}-\mathrm{V}_{\mathrm{P}} \mathrm{V}_{\mathrm{st}}\left(\mathrm{g}_{\mathrm{st}} \sin \left(\theta_{\mathrm{P}}-\theta_{\mathrm{st}}\right)-\mathrm{b}_{\mathrm{st}} \cos \left(\theta_{\mathrm{P}}-\theta_{\mathrm{st}}\right)\right)$

The main constraint of the STATCOM while operating is that, the active power exchange via the DC link should be zero i.e.

$\mathrm{PEx}=\operatorname{Re}\left(\mathrm{V}_{\text {sh }}\right.$ ISH $\left._{\text {H }}^{*}\right)=0$

Where,

$$
\operatorname{Re}\left(\mathrm{V}_{\mathrm{st}} \mathrm{I}_{\mathrm{st}}\right)=\mathrm{V}_{\mathrm{st}}^{2} \mathrm{~g}_{\mathrm{st}}-\mathrm{V}_{\mathrm{P}} \mathrm{V}_{\mathrm{st}}\left(\mathrm{g}_{\mathrm{st}} \cos \left(\theta_{\mathrm{P}}-\theta_{\mathrm{st}}\right)-\mathrm{b}_{\mathrm{st}} \sin \left(\theta_{\mathrm{P}}-\theta_{\mathrm{st}}\right)\right)
$$

The bus control restraint will be,

$$
\mathrm{F}=\mathrm{V}_{\mathbf{i}}-\mathrm{V}_{\text {spec }}=0
$$

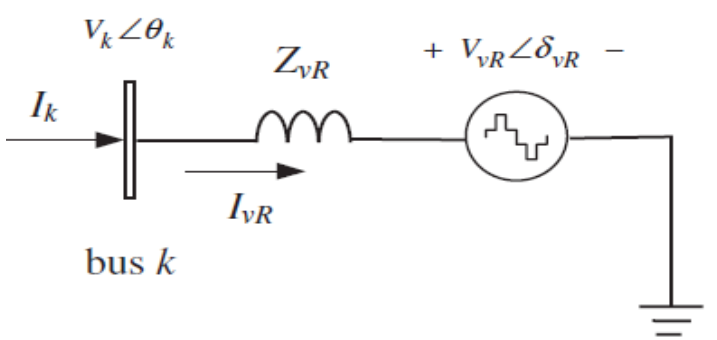

Fig 3: Static compensator (STATCOM) equivalent circuit

The bus at which the STATCOM is connected is represented as a PV bus, which may change to a PQ bus in the event of limits being violated. In such a case, the generated or absorbed reactive power would correspond to the violated limit. Unlike the SVC, the STATCOM is represented as a voltage source for the full range of operation, enabling a more robust voltage support mechanism. The STATCOM equivalent circuit shown in Figure 3 is used to derive the mathematical model of the controller for inclusion in power flow algorithms. The power flow equations for the STATCOM are derived below from first principles and assuming the following voltage source representation:

$\mathrm{E}_{\mathrm{vR}}=\mathrm{V}_{\mathrm{vR}}\left(\cos \delta_{\mathrm{VR}}+\mathrm{j} \sin \delta_{\mathrm{VR}}\right)$

Based on the shunt connection shown in Figure the following may be written:

$\mathrm{S}_{\mathrm{VR}}=\mathrm{V}_{\mathrm{VR}} \mathrm{I}_{\mathrm{V} R}^{*}=\mathrm{V}_{\mathrm{VR}} \mathrm{Y}_{\mathrm{VR}}^{*}\left(\mathrm{~V}_{\mathrm{VR}}^{*}-\mathrm{V}_{\mathrm{k}}^{*}\right)$

After performing some complex operations, the following active and reactive power equations are obtained for the converter and bus k, respectively:

$$
\begin{aligned}
& \mathrm{P}_{\mathrm{VR}}=\mathrm{V}_{\mathrm{vR}}^{2} \mathrm{G}_{\mathrm{vR}}+\mathrm{V}_{\mathrm{vR}} \mathrm{V}_{\mathrm{k}}\left[\mathrm{G}_{\mathrm{vR}} \cos \left(\delta_{\mathrm{vR}}-\theta_{\mathrm{k}}\right)\right. \\
& \left.+\mathrm{B}_{\mathrm{vR}} \sin \left(\delta_{\mathrm{vR}}-\theta_{\mathrm{k}}\right)\right] \\
& \mathrm{Q}_{\mathrm{vR}}=-\mathrm{V}_{\mathrm{vR}}^{2} \mathrm{~B}_{\mathrm{vR}}+\mathrm{V}_{\mathrm{vR}} \mathrm{V}_{\mathrm{k}}\left[\mathrm{G}_{\mathrm{vR}} \sin \left(\delta_{\mathrm{vR}}-\theta_{\mathrm{k}}\right)\right. \\
& \left.-\mathrm{B}_{\mathrm{vR}} \cos \left(\delta_{\mathrm{vR}}-\theta_{\mathrm{k}}\right)\right]
\end{aligned}
$$

$\mathrm{P}_{\mathrm{k}}=\mathrm{V}_{\mathrm{k}}^{2} \mathrm{G}_{\mathrm{vR}}+\mathrm{V}_{\mathrm{k}} \mathrm{V}_{\mathrm{vR}}\left[\mathrm{G}_{\mathrm{vR}} \cos \left(\theta_{\mathrm{k}}-\delta_{\mathrm{vR}}\right)\right.$

$\left.+\mathrm{B}_{\mathrm{VR}} \sin \left(\theta_{\mathrm{k}}-\delta_{\mathrm{VR}}\right)\right]$

$$
\begin{aligned}
& \mathrm{Q}_{\mathrm{k}}=-\mathrm{V}_{\mathrm{k}}^{2} \mathrm{~B}_{\mathrm{vR}}+\mathrm{V}_{\mathrm{k}} \mathrm{V}_{\mathrm{vR}}\left[\mathrm{G}_{\mathrm{vR}} \sin \left(\theta_{\mathrm{k}}-\delta_{\mathrm{vR}}\right)\right. \\
& \left.-\mathrm{B}_{\mathrm{vR}} \cos \left(\theta_{\mathrm{k}}-\delta_{\mathrm{vR}}\right)\right]
\end{aligned}
$$

Using these power equations, the linearised STATCOM model is given below, where the voltage magnitude $\mathrm{V}_{\mathrm{VR}}$ and phase angle $\delta_{\mathrm{vR}}$ are taken to be the state variables:

$$
\begin{aligned}
& {\left[\begin{array}{c}
\Delta \mathrm{P}_{\mathrm{k}} \\
\Delta \mathrm{Q}_{\mathrm{k}} \\
\Delta \mathrm{P}_{\mathrm{vR}} \\
\Delta \mathrm{Q}_{\mathrm{VR}}
\end{array}\right]=\left[\begin{array}{cccc}
\frac{\partial \mathrm{P}_{\mathrm{k}}}{\partial \theta_{\mathrm{k}}} & \frac{\partial \mathrm{P}_{\mathrm{k}}}{\partial \mathrm{V}_{\mathrm{k}}} \mathrm{V}_{\mathrm{k}} & \frac{\partial \mathrm{P}_{\mathrm{k}}}{\partial \delta_{\mathrm{VR}}} & \frac{\partial \mathrm{P}_{\mathrm{k}}}{\partial \mathrm{V}_{\mathrm{vR}}} \mathrm{V}_{\mathrm{vR}} \\
\frac{\partial \mathrm{Q}_{\mathrm{k}}}{\partial \theta_{\mathrm{k}}} & \frac{\partial \mathrm{Q}_{\mathrm{k}}}{\partial \mathrm{V}_{\mathrm{k}}} \mathrm{V}_{\mathrm{k}} & \frac{\partial \mathrm{Q}_{\mathrm{k}}}{\partial \delta_{\mathrm{VR}}} & \frac{\partial \mathrm{Q}_{\mathrm{k}}}{\partial \mathrm{V}_{\mathrm{vR}}} \mathrm{V}_{\mathrm{vR}} \\
\frac{\partial \mathrm{P}_{\mathrm{VR}}}{\partial \theta_{\mathrm{k}}} & \frac{\partial \mathrm{P}_{\mathrm{VR}}}{\partial \mathrm{V}_{\mathrm{k}}} \mathrm{V}_{\mathrm{k}} & \frac{\partial \mathrm{P}_{\mathrm{VR}}}{\partial \delta_{\mathrm{VR}}} & \frac{\partial \mathrm{P}_{\mathrm{VR}}}{\partial \mathrm{V}_{\mathrm{vR}}} \mathrm{V}_{\mathrm{vR}} \\
\frac{\partial \mathrm{Q}_{\mathrm{VR}}}{\partial \theta_{\mathrm{k}}} & \frac{\partial \mathrm{Q}_{\mathrm{VR}}}{\partial \theta_{\mathrm{k}}} \mathrm{V}_{\mathrm{k}} & \frac{\partial \mathrm{Q}_{\mathrm{VR}}}{\partial \theta_{\mathrm{k}}} & \frac{\partial \mathrm{Q}_{\mathrm{VR}}}{\partial \theta_{\mathrm{k}}} \mathrm{V}_{\mathrm{vR}}
\end{array}\right]\left[\begin{array}{c}
\Delta \theta_{\mathrm{k}} \\
\frac{\Delta \mathrm{V}_{\mathrm{k}}}{\mathrm{V}_{\mathrm{k}}} \\
\Delta \delta_{\mathrm{VR}} \\
\frac{\Delta \mathrm{V}_{\mathrm{VR}}}{\mathrm{V}_{\mathrm{vR}}}
\end{array}\right]} \\
& \frac{\partial \mathrm{P}_{\mathrm{k}}}{\partial \theta_{\mathrm{k}}}=-\mathrm{Q}_{\mathrm{k}}-\mathrm{V}_{\mathrm{k}}^{2} \mathrm{G}_{\mathrm{vR}} \\
& \frac{\partial \mathrm{P}_{\mathrm{k}}}{\partial \delta_{\mathrm{VR}}}=-\mathrm{V}_{\mathrm{k}} \mathrm{V}_{\mathrm{vR}}\left[\mathrm{G}_{\mathrm{VR}} \sin \left(\theta_{\mathrm{k}}-\delta_{\mathrm{VR}}\right)-\right. \\
& \left.\mathrm{B}_{\mathrm{vR}} \cos \left(\theta_{\mathrm{k}}-\delta_{\mathrm{vR}}\right)\right] \\
& \frac{\partial \mathrm{P}_{\mathrm{VR}}}{\partial \delta_{\mathrm{VR}}}=-\mathrm{Q}_{\mathrm{VR}}-\mathrm{V}_{\mathrm{vR}}^{2} \mathrm{~B}_{\mathrm{VR}} \\
& \frac{\partial \mathrm{P}_{\mathrm{VR}}}{\partial \theta_{\mathrm{k}}}=\mathrm{V}_{\mathrm{vR}} \mathrm{V}_{\mathrm{k}}\left[\mathrm{G}_{\mathrm{VR}} \sin \left(\delta_{\mathrm{VR}}-\theta_{\mathrm{k}}\right)-\right. \\
& \left.\mathrm{B}_{\mathrm{vR}} \cos \left(\delta_{\mathrm{vR}}-\theta_{\mathrm{k}}\right)\right]
\end{aligned}
$$


$\frac{\partial P_{k}}{\partial V_{k}} V_{k}=P_{k}+V_{k}^{2} G_{v R}$
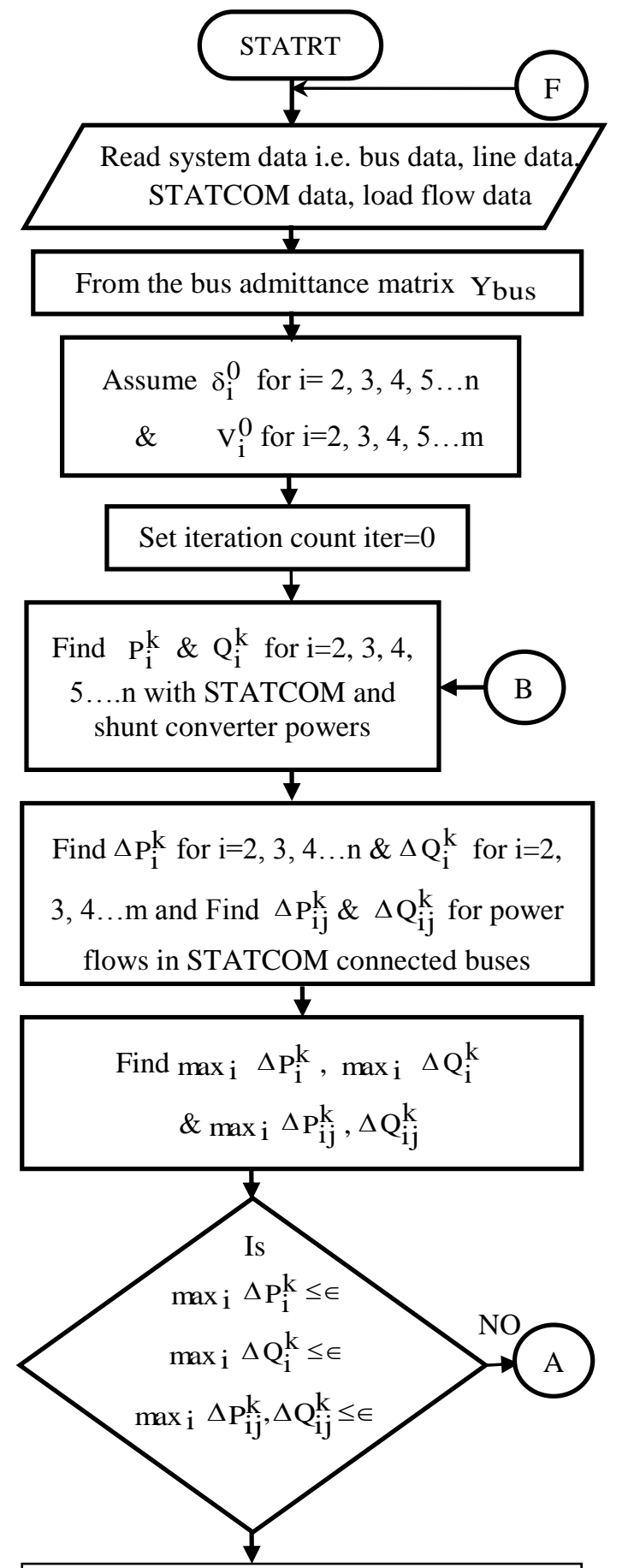

Find slack bus power $\&$ all lines power $\&$ line flows

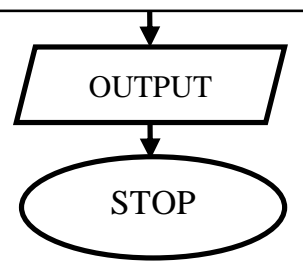

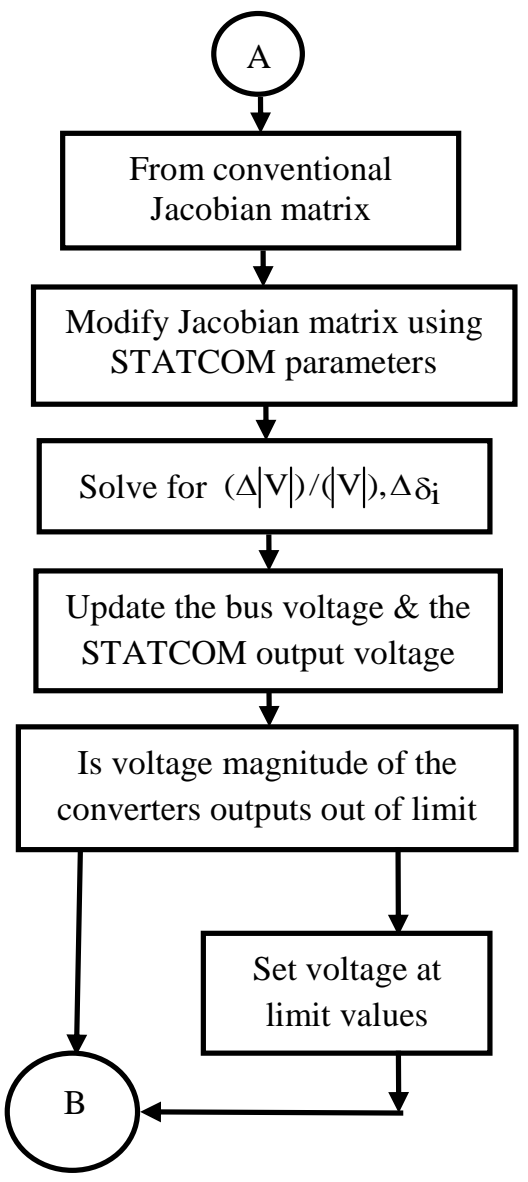

Fig 4: STATCOM with power flow Flow-chart

$$
\begin{aligned}
& \frac{\partial \mathrm{P}_{\mathrm{k}}}{\partial \mathrm{V}_{\mathrm{vR}}} \mathrm{V}_{\mathrm{vR}}=\mathrm{V}_{\mathrm{k}} \mathrm{V}_{\mathrm{vR}}\left[\mathrm{G}_{\mathrm{vR}} \cos \left(\theta_{\mathrm{k}}-\delta_{\mathrm{vR}}\right)+\right. \\
& \left.\mathrm{B}_{\mathrm{VR}} \sin \left(\theta_{\mathrm{k}}-\delta_{\mathrm{vR}}\right)\right] \\
& \frac{\partial P_{v R}}{\partial V_{v R}} V_{v R}=P_{v R}+V_{v R}^{2} G_{v R} \\
& \frac{\partial \mathrm{P}_{\mathrm{VR}}}{\partial \mathrm{V}_{\mathrm{k}}} \mathrm{V}_{\mathrm{k}}=\mathrm{V}_{\mathrm{vR}} \mathrm{V}_{\mathrm{k}}\left[\mathrm{G}_{\mathrm{vR}} \cos \left(\delta_{\mathrm{VR}}-\theta_{\mathrm{k}}\right)+\right. \\
& \left.\mathrm{B}_{\mathrm{VR}} \sin \left(\delta_{\mathrm{vR}}-\theta_{\mathrm{k}}\right)\right] \\
& \frac{\partial \mathrm{Q}_{\mathrm{k}}}{\partial \theta_{\mathrm{k}}}=\mathrm{P}_{\mathrm{k}}-\mathrm{V}_{\mathrm{k}}^{2} \mathrm{G}_{\mathrm{vR}} \\
& \frac{\partial \mathrm{Q}_{\mathrm{k}}}{\partial \delta_{\mathrm{VR}}}=-\mathrm{V}_{\mathrm{k}} \mathrm{V}_{\mathrm{vR}}\left[\mathrm{G}_{\mathrm{VR}} \cos \left(\theta_{\mathrm{k}}-\delta_{\mathrm{vR}}\right)+\right. \\
& \left.\mathrm{B}_{\mathrm{vR}} \sin \left(\theta_{\mathrm{k}}-\delta_{\mathrm{vR}}\right)\right] \\
& \frac{\partial \mathrm{Q}_{\mathrm{VR}}}{\partial \delta_{\mathrm{VR}}}=\mathrm{P}_{\mathrm{vR}}-\mathrm{V}_{\mathrm{vR}}^{2} \mathrm{G}_{\mathrm{VR}}
\end{aligned}
$$




$$
\begin{aligned}
& \frac{\partial \mathrm{Q}_{\mathrm{VR}}}{\partial \theta_{\mathrm{k}}}=-\mathrm{V}_{\mathrm{vR}} \mathrm{V}_{\mathrm{k}}\left[\mathrm{G}_{\mathrm{VR}} \cos \left(\delta_{\mathrm{VR}}-\theta_{\mathrm{k}}\right)+\right. \\
& \left.\mathrm{B}_{\mathrm{VR}} \sin \left(\delta_{\mathrm{vR}}-\theta_{\mathrm{k}}\right)\right] \\
& \frac{\partial \mathrm{Q}_{\mathrm{k}}}{\partial \mathrm{V}_{\mathrm{k}}} \mathrm{V}_{\mathrm{k}}=\mathrm{Q}_{\mathrm{k}}-\mathrm{V}_{\mathrm{k}}^{2} \mathrm{~B}_{\mathrm{vR}} \\
& \frac{\partial \mathrm{Q}_{\mathrm{k}}}{\partial \mathrm{V}_{\mathrm{VR}}} \mathrm{V}_{\mathrm{vR}}=-\mathrm{V}_{\mathrm{k}} \mathrm{V}_{\mathrm{vR}}\left[\mathrm{G}_{\mathrm{VR}} \sin \left(\theta_{\mathrm{k}}-\delta_{\mathrm{VR}}\right)-\right. \\
& \left.\mathrm{B}_{\mathrm{VR}} \cos \left(\theta_{\mathrm{k}}-\delta_{\mathrm{VR}}\right)\right] \\
& \frac{\partial Q_{v R}}{\partial V_{v R}} V_{v R}=Q_{v R}-V_{k}^{2} B_{v R} \\
& \frac{\partial \mathrm{Q}_{\mathrm{VR}}}{\partial \mathrm{V}_{\mathrm{k}}} \mathrm{V}_{\mathrm{k}}=-\mathrm{V}_{\mathrm{vR}} \mathrm{V}_{\mathrm{k}}\left[\mathrm{G}_{\mathrm{VR}} \sin \left(\delta_{\mathrm{VR}}-\theta_{\mathrm{k}}\right)-\right. \\
& \left.\mathrm{B}_{\mathrm{VR}} \cos \left(\delta_{\mathrm{VR}}-\theta_{\mathrm{k}}\right)\right]
\end{aligned}
$$

\section{SINGLE PHASE FAULT}

An electric power system consists of generators, transformers, transmission lines and consumer equipment. The system must be protected against flow of heavy short circuit currents, which can cause permanent damage to major equipments, by disconnecting the faulty section of system by means of circuit breaker and protective relaying. Such conditions are caused in the system accidentally through insulation failure of equipment or flashover of lines initiated by a lightning stroke or through accidental faulty operation. Any abnormal conditions which causes flow of huge current in the conductors or cable through inappropriate paths in the circuit can be defined as a fault [10]

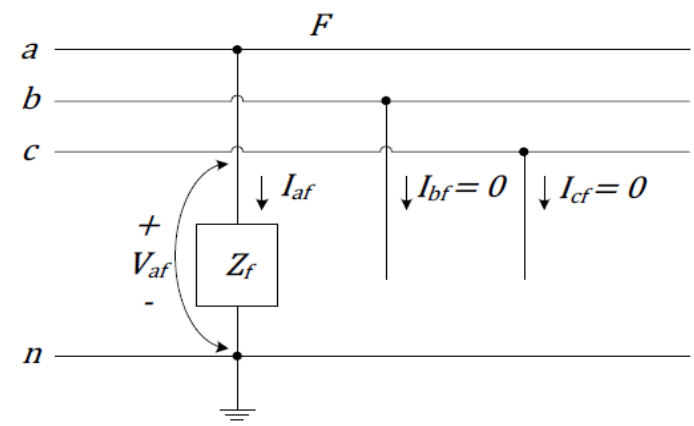
Fig 5: General Representation of Single Line-Ground
Fault.

In normal operating conditions all the circuit elements of an electrical system carry currents whose magnitude depends upon the value of the generator voltage and the effective impedances of all the power transmission and distribution system elements including the impedances of the loads usually relatively larger than other impedances. Faults usually occur in a power system due to insulation failure, flashover, physical damage or human error. This fault's may either be three phase in nature involving all three phases in a symmetrical manner, or may be asymmetrical where usually only one or two phases may be involved. Faults may also be caused by either short-circuits to earth or between live conductors, or may be caused by broken conductors in one or more phases. Sometimes simultaneous faults may occur involving both short-circuit and broken conductor fault's (also known as open-circuit faults).

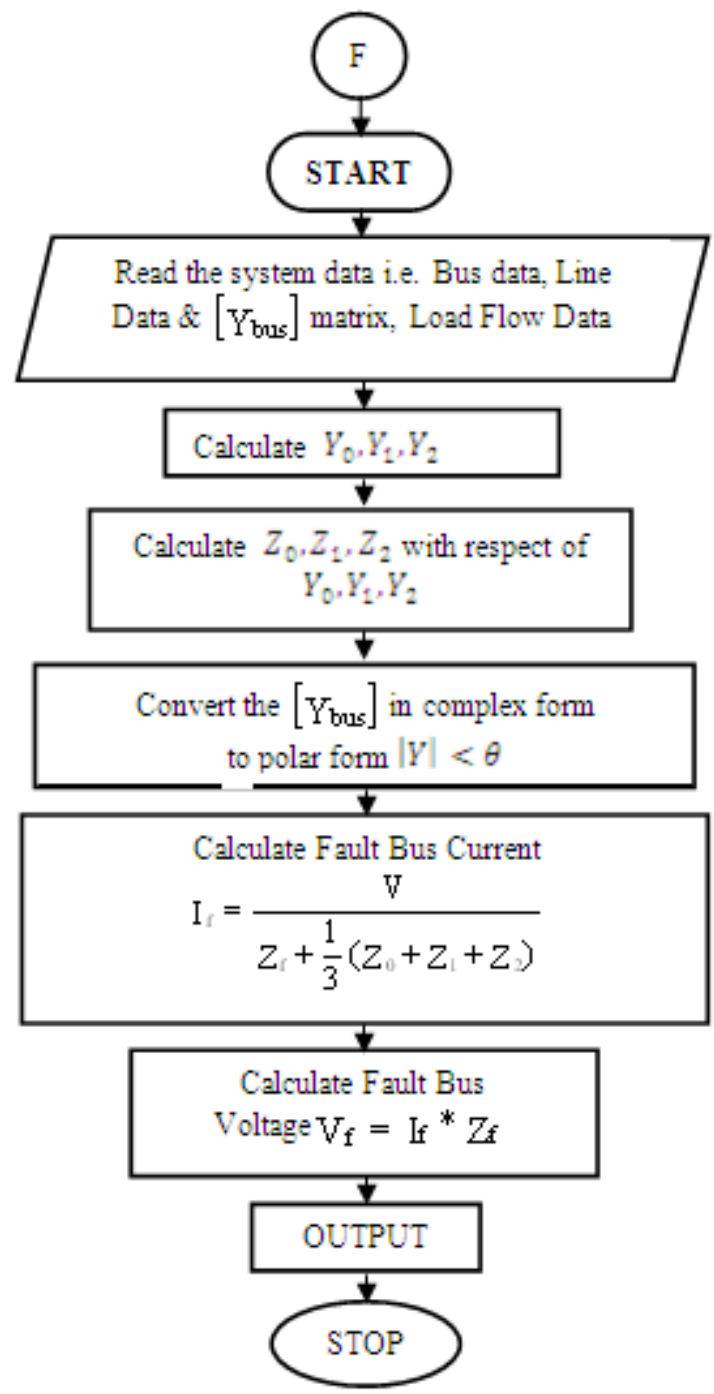

Fig 6: Single Line-Ground Fault Flow-chart.

These papers consider an L-G fault [9] with fault impedance $\mathrm{Z}_{\mathrm{f}}$ as shown in figure. Suppose fault is occurring at bus ' $\mathrm{a}$ ', then the effected fault bus voltage can be determined by using the equation [9].

$$
\begin{aligned}
& \mathrm{V}=\mathrm{I}_{\mathrm{a}} * \mathrm{Z}_{\mathrm{f}} \\
& \mathrm{I}_{\mathrm{b}}=\mathrm{I}_{\mathrm{c}}=0
\end{aligned}
$$

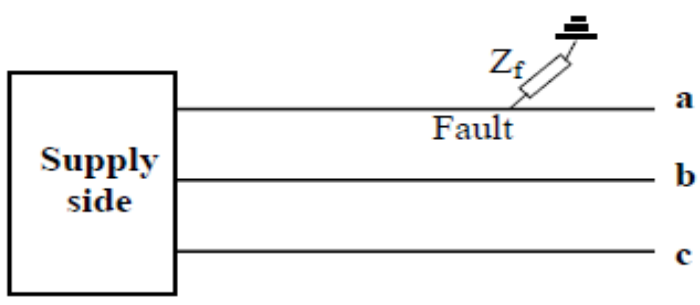

Fig 7: 3-phase Line-Ground Fault With Fault Impedance. 
Mathematical analysis using the network equation in symmetrical components would yield the desired result for the fault current If as:

$$
I_{a}=\frac{3 V}{3 Z_{f}+\left(Z_{0}+Z_{1}+Z_{2}\right)}
$$

\section{SIMULATION RESULTS AND DISCUSSIONS}

This paper is presented in the concept of power system Fault with STATCOM FACTS controller

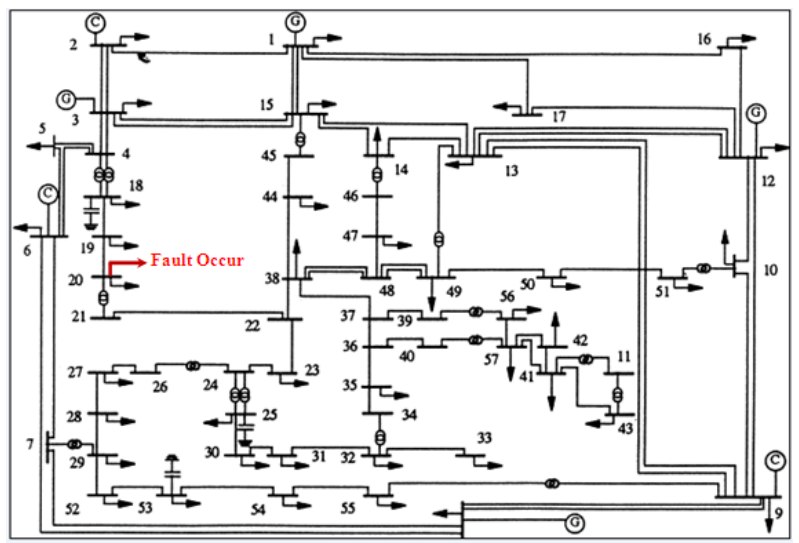

Fig 8: IEEE-57 bus syatem: fault occur in bus No-20

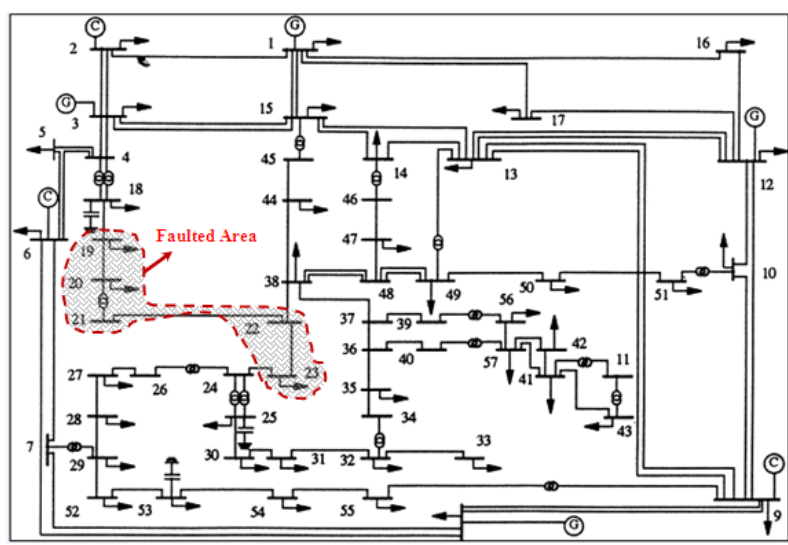

Fig 9: IEEE-57 bus syatem: faulted area.

This paper is presented the first approach of IEEE-57 bus system fault with STATCOM FACTS controller program has been developed on MATLAB platform. Formulate and Assemble Y-bus in Per Unit \& STATCOM data. Assign Initial Guesses to Unknown Voltage Magnitudes and Angles for a Flat Start $|V|=1.0 \& \delta=0$. Determine the fault current \& fault bus voltage using the equation and call the fault program in main STATCOM program. Determine the modify Jacobian Matrix $J$ for Iteration $k$. Find $P_{i}^{k} \& Q_{i}^{k}$ with STATCOM shunt converter powers. Finally compute voltage magnitude and angle.

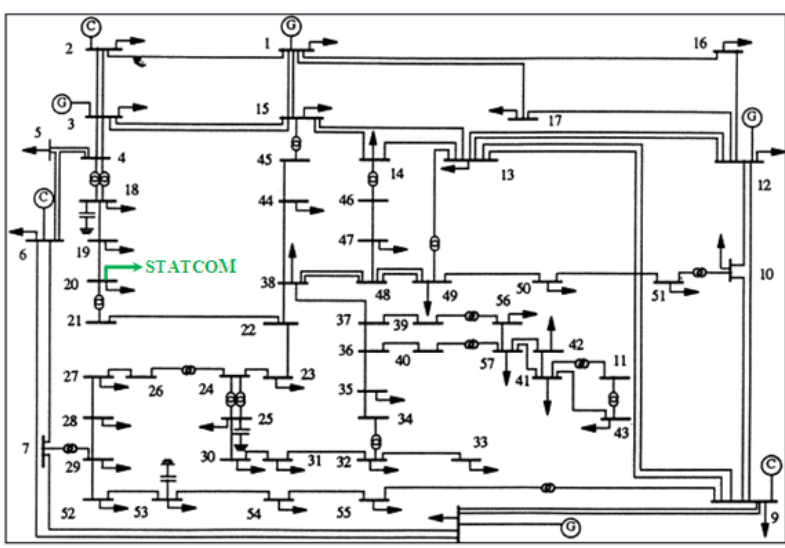

Fig 10: IEEE-57 bus system: STATCOM connected in bus No-20.

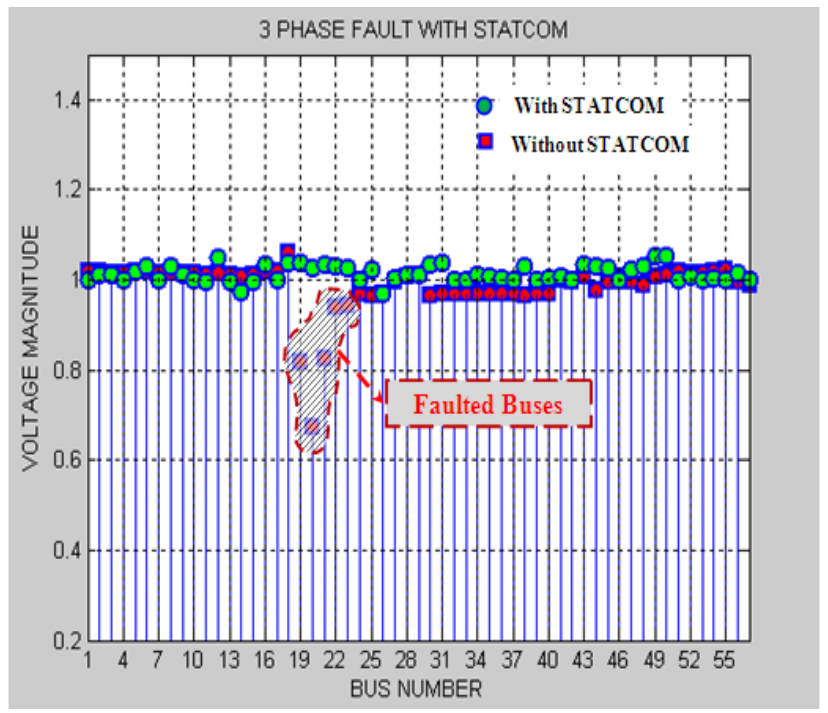

Fig 10: MATLAB Output of IEEE-57 Bus System Fault with \& without STATCOM.

Table 1. Effected fault bus voltage magnitude and angle With \& without STATCOM

\begin{tabular}{|c|c|c|c|c|}
\hline \multicolumn{2}{|c|}{ Fault Without STATCOM } & \multicolumn{2}{c|}{$\begin{array}{c}\text { Fault With } \\
\text { STATCOM }\end{array}$} \\
\hline $\begin{array}{c}\text { Buse } \\
\text { s }\end{array}$ & $\mathrm{V}$ & $\delta$ & $\mathrm{V}$ & $\delta$ \\
\hline 18 & 1.0593 & 60.6906 & 1.0256 & 58.7364 \\
\hline 19 & 0.8192 & 46.9378 & 1.0207 & 58.4837 \\
\hline $\mathbf{2 0}$ & $\mathbf{0 . 6 7 4 3}$ & $\mathbf{3 8 . 6 3 4 6}$ & $\mathbf{1 . 0 0 0 0}$ & $\mathbf{5 7 . 2 9 5 8}$ \\
\hline 21 & 0.8245 & 47.2376 & 1.0107 & 57.3958 \\
\hline 22 & 0.9399 & 53.8511 & 1.0276 & 58.8763 \\
\hline 23 & 0.9416 & 53.9482 & 1.0269 & 58.8396 \\
\hline
\end{tabular}




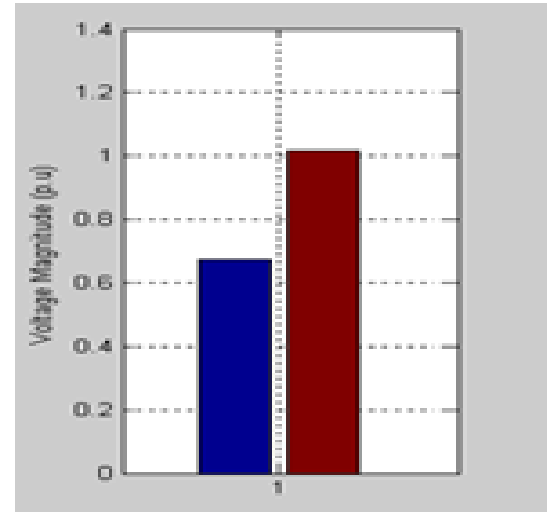

Graph1: Comparison between 3 phase fault bus voltages Magnitude with \& without STATCOM

Fault Bus No-20 Voltage Magnitude-0.6743

With STATCOM Bus-20 Voltage Magnitude-1.0

\section{CONCLUSION}

This paper presents a comparative model to describe a voltage dip condition with and without STATCOM. It has demonstrated the static mechanism of the voltage dip phenomenon using an IEEE 57 bus system model which includes a fault. The results of simulations on the IEEE 57 bus test system have clearly shown that how STATCOM devices increased the area bus voltage level during fault condition and also improve the angle of IEEE 57 bus system. It is believed that this paper may provide a deeper insight into the static mechanism of voltage dip phenomenon and effect of STATCOM on voltage dip condition.

\section{REFERENCES}

[1] Acha, E, C.R. Fuerte-Esquivel, H. Ambriz-Perez and C. Angeles-Camacho, FACTS modeling and simulation in

Power Networks $1^{\text {st }}$ Edn. John Wiley and Sons Inc., New York, ISBN: 978-0470852712, 2004.

[2] M. A. Abdel-Moamen and N. P. Padhy, "Optimal Power Flow Incorporating FACTS Devices Bibliography and Survey", IEEE PES Transmission and Distribution Conference and Exposition, 7-12 September 2003, vol. 2, pp. $669-676$.

[3] Determination of Needed Facts Controller that Increase Asset Utilization of Power System - L.A.S. Pilotto, W. W. Ping, Carvallho, Wey, Long and Edris -IEEE transaction on power delivery vol. 12 No. 1, January 1997.

[4] Xia Jiang Xinghao Fang Chow, J.H. Edris, A.-A. Uzunovic, E. Parisi, M. Hopkins, L. "A Novel Approach for Modeling Voltage-Sourced Converter-Based FACTS Controllers", IEEE Transactions on Power Delivery, Vol 23(4), Oct 2008.

[5] Johnson, B.K. "How series and combined multiterminal controllers FACTS controllers function in an AC transmission system", IEEE Power Engineering Society General Meeting, Vol.2, pp 1265-1267, June 2004.

[6] Tyll.H.K. "FACTS Technology for Reactive Power Compensation and System Control", IEEE/PES Conference on Transmission and Distribution, 2004, pp.976-980, Nov. 2004.

[7] Jong, Su Yoon Soo, Yeol Kim Yong, Hak Kim Kyu, Chul Lee Chang, Keun Lee, "The analysis of STATCOM and SVC Cooperation Effect", Transmission and Distribution Conference, Asia and pacific, 2009, pp1-5, Oct 2009.

[8] Spector, Ding Lijie Liu, Yang Miao Yiqun, "Comparison of High Capacity SVC and STATCOM in Real power Grid", International Conference on Intelligent Computation Technology and Automation, Vol.1,pp.993997,May2010.

[9] Wadhwa, C.L., Electrical Power Systems, New Delhi, New Age International publishers, 2005.

[10] Saadat, Hadi, Power System Analysis, New Delhi, Tata McGraw-Hill Publishing Company Limited, 2002. 